\title{
Protective Effect of Parsley Juice (Petroselinum crispum, Apiaceae) against Cadmium Deleterious Changes in the Developed Albino Mice Newborns (Mus musculus) Brain
}

\author{
Ahmed A. Allam, ${ }^{1,2}$ Salah N. Maodaa, ${ }^{1}$ Rasha Abo-Eleneen, ${ }^{2}$ and Jamaan Ajarem ${ }^{1}$ \\ ${ }^{1}$ Department of Zoology, College of Science, King Saud University, Riyadh 11451, Saudi Arabia \\ ${ }^{2}$ Department of Zoology, Faculty of Science, Beni-Suef University, Beni-Suef 62511, Egypt \\ Correspondence should be addressed to Ahmed A. Allam; aallam@ksu.edu.sa
}

Received 13 October 2015; Revised 13 December 2015; Accepted 30 December 2015

Academic Editor: Denis Delic

Copyright ( $) 2016$ Ahmed A. Allam et al. This is an open access article distributed under the Creative Commons Attribution License, which permits unrestricted use, distribution, and reproduction in any medium, provided the original work is properly cited.

\begin{abstract}
Parsley was used as a probe of the current experiment to prevent the behavioral, morphological and biochemical changes in the newborn brain following the administration of cadmium $(\mathrm{Cd})$ to the pregnant mice. The nonanesthetized pregnant mice were given daily parsley juice (Petroselinum crispum) at doses of $20 \mathrm{mg} / \mathrm{kg}$ and $10 \mathrm{mg} / \mathrm{kg}$. Pregnant mothers were given Cd at a dose of $30 \mathrm{mg} / \mathrm{kg}$ divided into 3 equal times. The newborns have been divided into 6 groups: Group A, mothers did not take treatment; Groups B and C, mothers were treated with low and high dose of parsley, respectively; Group D, mothers were treated only with Cd (perinatal intoxication); Groups E and F, mothers were treated with Cd doses and protected by low and high doses of parsley, respectively. Light microscopy showed that $\mathrm{Cd}$-induced neuronal degeneration by chromatolysis and pyknosis in the brain regions. The low dose of parsley $10 \mathrm{~g} / \mathrm{kg} /$ day exhibited significant effects in neutralizing and reducing the deleterious changes due to Cd exposure during pregnancy on the behavioral activities, neurotransmitters, oxidative stress, and brain neurons morphology of the mice newborns.
\end{abstract}

\section{Background}

Cadmium (Cd) exposure produces severe toxicity in multiple organ tissues because it produces oxidative stress, disrupts aquaporins, and interferes with functions of essential cations such as zinc and magnesium [1]. Cd causes high risks to the young, as exposures early in life during development [2]. It is classified as one of the most toxic and carcinogenic metals [3]. It was reported as a serious industrial and environmental pollutant and may cause serious health hazards to humans and animals [4]. Many sources of Cd exposure for humans and animals could be from several industries (such as petroleum mining, metal plating, pigments, plastics, batteries, toys, and alloy), cigarette smoking, or dietary consumption [5]. Exposure to Cd may cause lesions in many organs such as central nervous system (CNS), liver, kidney, and testis $[1,3,6]$.
The long-term changes in neurobehaviors such as alterations in attention and memory as well as in the psychomotor and vasomotor functioning and speed in workers are due to $\mathrm{Cd}$ exposure [7]. Moreover, rat studies have observed increased aggressive and anxiety-like behaviors, impaired learning and memory processes, and changes in the development of the visual system [8]. Some studies on Cd toxicity have found an association with behavioral disturbances and cholinergic neurotransmission since an increase or a decrease in the acetylcholine esterase activity was verified in both animal models and humans that showed behavioral impairments after exposure to Cd [9]. This enzyme hydrolyses the neurotransmitter acetylcholine in the synaptic cleft of cholinergic synapses and neuromuscular junctions [10]. Alterations in the acetylcholine activity in various diseases and poisonings suggest that this enzyme could be an important physiological 
and pathological parameter [11]. In addition, maternal $\mathrm{Cd}$ exposure during pregnancy induced fetal growth restriction [12]. Nevertheless, the molecular mechanism for Cd-induced development toxicity remains obscure.

$\mathrm{Cd}$ has well-documented teratogen and embryotoxic effects in a large variety of species, including man [13]. Cd is more toxic to newborns and young rats than to adult [14]. This metal accumulates in the brain of developing and adult rats [11] leading to brain intracellular accumulation, cellular dysfunction, and cerebral edema. Also, it can affect the degree and balance of excitation-inhibition in synaptic neurotransmission as well as the antioxidant levels in animal brain [15]. Cd embryotoxicity is partly due to oxidative DNA damage associated with increased producing of oxygen reactive species (ROS) and decreased antioxidant enzyme levels, and the interaction of $\mathrm{Cd}$ with the enzymes that repair damaged DNA [16]. Many culinary herbs (e.g., parsley) have been shown to function as natural antioxidants [17].

Parsley (Petroselinum crispum, Apiaceae) is an annual herb which is important dietary source of vitamins and essential metals. Its supplementation at sufficient levels can promote the levels of the vitamins and essential metals in the human body, which in turn can decrease the risks of Cd toxicity [18]. Phytochemical screening of parsley has revealed the presence of some compounds such as flavonoids [19], carotenoids [20], ascorbic acid [21], and tocopherol [22]. These components of fresh parsley leaf scavenge superoxide anion in vitro and hydroxyl radical in addition to protecting against ascorbic acid-induced membrane oxidation [19], where lipid oxidation is a major cause of food quality deterioration. Supplementation of diets with fresh parsley leaf can increase antioxidant capacity of rat plasma and decrease oxidative stress in humans [23]. Similarly, aqueous and ethanol extracts of fresh parsley leaf strongly inhibit linoleic acid oxidation and lipid oxidation [24].

Parsley is reported as a good source of antioxidant which may prevent Cd toxicity and teratogenicity. Also, it is one of the most used medicinal plants to treat arterial hypertension [25], diabetes, cardiac [25], and renal diseases [26]. Moreover, in experimental studies, it has been reported that this herb has strong diuretic [27], antihyperglycemic [28], antihyperlipidemic, anticoagulant [29], antioxidant [30], antimicrobial [31], and laxative activities [32]. Alcoholic extract of parsley has a protective effect against toxicity induced by sodium valproate (SVP) in male rats [33]. Parsley leaf was used for treatment of constipation, jaundice, colic, flatulence edema, and rheumatism. It was used as an aphrodisiac, improved productive performance in broiler, antimicrobial, antianemia, hemorrhagic, anticoagulant, antihyperlipidemic, antihepatotoxic, and laxative $[32,33]$. It was used to treat eczema, knee, ache, impotence, and bleed [34]. However, according to our knowledge, no investigations have been reported in the literature on the protective effect of parsley against $\mathrm{Cd}$ teratogenicity.

In the present work we investigated the hypothesis of the protective effect of parsley juice against $\mathrm{Cd}$ intoxication during pregnancy and lactation periods in albino mice newborns. Behavioral and motor performances of newborns have been investigated. Also, we have evaluated the effects of this metal on oxidative stress, neurotransmitter activities, and brain structures of the newborns.

\section{Methods}

2.1. Chemicals. The current cadmium chloride $\left(\mathrm{CdCL}_{2}\right)$ and other chemicals have been purchased from Sigma Company (St. Louis, MO, USA).

\subsection{Parsley Juice Preparation. Petroselinum crispum (Mill.)} Nym. ex A.W. Hill from the family Apiaceae (alt. Umbelliferae) is commonly known as parsley. The origin of parsley is from Mediterranean region, but today it is cultivated wherever of the world. Botanic identification was performed by taxonomist in the Department of Botany and Microbiology, Collage of Sciences, King Saud University, Riyadh, Saudi Arabia. The plain leaf of parsley type was daily collected from vegetable market in Riyadh (Saudi Arabia) and was carefully washed under tap water. The fresh parsley juice was prepared daily using a vegetable juices machine. Two concentrations of the juice were prepared: the first is $10 \%$ juice, that is, $10 \mathrm{~g}$ parsley squash in $100 \mathrm{~mL}$ drinking water. The second is $5 \%$ juice, that is, $5 \mathrm{~g}$ parsley squash in $100 \mathrm{~mL}$ drinking water. The prepared juice has been filtered using a filter paper after preparation and before drinking by the animals to remove fibers and other insoluble materials.

2.3. Ethics Statement. All the experimental protocols and investigations were approved and complied with the Guide of Laboratory Animals Use and Care which have been published by the United States of America National Institutes of Health (NIH Publication number 85-23, revised 1996) and have been approved by the Animal Experimentation Ethics Committee at the King Saud University (Permit number: PT 983).

2.4. Animals and Dosing Schedule. The current study used a total of 45 albino mice (Mus musculus), 15 mature males and 30 mature virgin females (weighing 30-35 g), collected from the animal house in the College of Pharmacy, King Saud University. The animals were housed in mouse cages (1 animal/cage) under pathogen-free and healthy conditions. Males and females lived at $22-25^{\circ} \mathrm{C}$ on a light/dark cycle $(12: 12 \mathrm{~h})$, in addition to provided water and food ad libitum. Mating was done between proesterous females and males overnight by housing of one female with one male in special cages used for mating (stainless steel wire cages). Vaginal plug deposition at morning determined the day zero of gestation. Parsley juice was orally administered daily to nonanesthetized parsley treated groups by gastric intubation at a dose of $20 \mathrm{~g} / \mathrm{kg} /$ day and $10 \mathrm{~g} / \mathrm{kg} /$ day from day zero of gestation till postnatal day 30 .

Totally, $30 \mathrm{mg} / \mathrm{kg}$ of $\mathrm{CdCl}_{2}$ was dissolved in $30 \mathrm{~mL}$ saline and intraperitoneally injected to partially anesthetized $\mathrm{Cd}$ treated groups on three stages: at day 7 of gestation, postnatal day 1 , and postnatal day 15 (10 $\mathrm{mg} / \mathrm{kg}$ every time). 

follows:

The mothers were labeled and divided into 6 groups as

Group A: pregnant mice were given tap water orally and saline intraperitoneally (did not take treatment as control group).

Group B: pregnant mice were given 5\% parsley juice orally and saline intraperitoneally ( $5 \%$ parsley group).

Group C: pregnant mice were given 10\% parsley juice orally and saline intraperitoneally (10\% parsley group).

Group D: pregnant mice were given tab water orally and Cd doses intraperitoneally (Cd intoxicated group).

Group E: pregnant mice were given 5\% parsley juice orally and Cd doses intraperitoneally (5\% parsley-Cd group).

Group F: pregnant mice were given $10 \%$ parsley juice orally and Cd doses intraperitoneally (10\% parsley-Cd group).

2.5. Newborns Body Weights Assessment during Lactation Period. A physical developmental landmark like body weight is a useful indicator of the development through the entire lactation period. Thus, the newborns were weighed every day from postnatal day 1 until day 28.

2.6. Cd Estimation Assay. The analytical determination of $\mathrm{Cd}$ in the brain was carried out according to Shah et al. [35] using Inductively Coupled Plasma Mass Spectrometer (ICPMS) under operation conditions of the instruments shown in Table (S1) (see Supplementary Material available online at http://dx.doi.org/10.1155/2016/2646840).

2.7. Behavioral Assays. Ten meal mice pups from each group (first generation) were investigated in the current study at postnatal day 30 (postweaning period). Each newborn was used only in one test. For tests conduction, the pups were brought into investigation room of dim red light used for this purpose $\left(25^{\circ} \mathrm{C}\right)$. The tests were done blindly by one experimenter according to Ajarem and Ahmad [36].

2.7.1. Cage Activity Assay. The Ugo Basile 47420-Activity Cage was used to record spontaneous coordinate activity in mice and variation of this activity in time either horizontal or vertical movements. This test was performed for $3 \mathrm{~min} /$ animal.

2.7.2. Grip-Strength Meter Assay. The Ugo Basile 47200 GripStrength Meter suitable for mice automatically measures Grip Strength (i.e., peak force and time resistance) of the forelimbs in mice. The aim was to assess forelimbs muscle strength. Each animal was tested three times and the peak force of each mouse was recorded. The mean of three values of each mouse was recorded.
2.7.3. Rota-Rod Assay. The Ugo Basile rota-rod instrument has been used to estimate the balance ability in the investigated animals. The newborns were placed on a horizontally oriented rod which mechanically rotates at $10 \times \mathrm{g}$. The newborns innately will try to stay on the rota-rod (rotating rod) and will try to avoid falling down on the instrument sensor. The length of time that the tested newborns stay on the rotarod was used as a measure of their coordination, physical condition, balance, and motor activity.

2.8. Biochemical Assays. Six newborns from each group were anesthetized by light ether and sacrificed by decapitation at postnatal day 30 . The brain was dissected and $0.5 \mathrm{~g}$ tissue was homogenized in $5 \mathrm{~mL}$ of cold $0.1 \mathrm{M} \mathrm{HClO} 4$ containing $0.05 \%$ EDTA. The homogenate was centrifuged at $1000 \times \mathrm{g}$ for $10 \mathrm{~min}$ at $4^{\circ} \mathrm{C}$ and the clear supernatant was collected in a microfuge tube $(0.5 \mathrm{~mL}$ each $)$ and was stored at $-40^{\circ} \mathrm{C}$ until used.

2.8.1. Dopamine and Serotonin Determination Assay. The levels of neurotransmitters serotonin or dopamine were estimated in the brain using the modified method of Eghwrudjakpor et al. [37] as mentioned by Abu-Taweel et al. [38].

2.8.2. Acetylcholine Determination Assay. The estimation of acetylcholine was done according to the method of Ichikawa et al. [39].

2.8.3. Lipid Peroxidation Assay. Lipid peroxidation was estimated by assessment of thiobarbituric acid-reactive substances (TBARS) using the method of Preuss et al. [40].

2.8.4. Glutathione (GSH) Assay. The reduced glutathione content was estimated using the modified method of Beutler et al. [41] as reported in Allam et al. [42].

2.8.5. Peroxidase Activity Determination Assay. Peroxidase enzyme activity was estimated using the procedure of Kar and Mishra [43].

2.9. Histological Studies Using Light Microscopy. Four pups of each group have been anesthetized using light ether and decapitated at postnatal day 30 followed by dissection. Histological preparations of the left loop of cerebellum, cerebral cortex, and medulla oblongata were done as mentioned by Allam et al. [42]. The use of Haematoxylin and Eosin stains for the paraffin sections was done according to the method of Mallory [44].

2.10. Statistical Analysis Assays. The current study data has been analyzed using the software program Statistical Package for the Social Sciences (SPSS for Windows version 11.0; SPSS Inc., Chicago). The comparative analyses were conducted by using the general linear models procedure (SPSS, Inc.). The data has been tested by one-way and two-way analysis of variance (ANOVA) followed by LSD computations to compare various groups with each other. Results were expressed as mean \pm SD. The level of significance was expressed as very 
highly significant at ${ }^{* * *} P<0.001$, highly significant at ${ }^{* *} P<$ 0.01 , and significant at ${ }^{*} P<0.05$.

\section{Results}

3.1. General Observations. The signals of toxicity due to Cd exposure were noticed postnatally in group D mothers represented by weakness and ataxia of hindlimb muscles causing alteration in maternal behavior, so their newborns suffered from bad lactation and consequently malnutrition. These signals of toxicity were reduced in groups $\mathrm{E}$ and $\mathrm{F}$ and especially group E due to parsley supplementation. The insignificant difference in letters size was observed in groups B, C, and E while highly significant and very highly significant reduction were detected in groups $\mathrm{F}$ and $\mathrm{D}$ (Figure 1(a)) compared to group A. The body weights of the pups of the present experimental groups were varied from postnatal day 1 to day 28 (Figure 1(b)). The pups of groups D, E, and F suffered from a noticeable decrease in the body weight gain especially group D. The pups of group E showed marked increase in their body weight gain by the third week of age to become near the values of normal pups.

The Cd concentration in the brain tissues was estimated in the brain tissues of the newborns. Figure 1(c) showed the $\mathrm{Cd}$ bioaccumulation in the brain of groups $\mathrm{B}$ and $\mathrm{C}$ was highly significantly reduced while in group $\mathrm{D}$ it was very highly significantly elevated and in groups $\mathrm{E}$ and $\mathrm{F}$ it was highly significantly elevated compared to group A. The current results showed that parsley significantly reduces the $\mathrm{Cd}$ concentration in pup's brain of parsley treated group.

3.2. Behavioral Investigations. In the activity cage and in comparison with the newborns of group A, the newborns of group $\mathrm{D}$ showed a significant elevation in the vertical and horizontal movement in comparison with group A. Contrary to the vertical movement, the newborns of groups $B$ and $C$ showed significant increase in the value of horizontal movement. Despite Cd and parsley treatment, the newborns of groups $\mathrm{E}$ and $\mathrm{F}$ displayed vertical and horizontal movement values near the values of normal newborns (Figures 2(a) and 2(b)).

The forelimb muscles of the newborns of groups A, B, and $C$ recorded relatively similar beaks in the grip strength examination scores. While the recorded beaks of group D newborns appeared significantly small, the beaks achieved by the newborns of groups $\mathrm{E}$ and $\mathrm{F}$ showed significant improvements (Figure 2(c)).

In rotator test and in comparison with the newborns of group $\mathrm{A}$, the time of group $\mathrm{D}$ pups on the rod was significantly small. The staying times of the newborns of groups B, C, E, and $\mathrm{F}$ on the rod were less than the time of group $\mathrm{A}$ but the difference was not significant (Figure 2(d)).

\subsection{Biochemical Studies}

3.3.1. Neurotransmitters. In groups $\mathrm{A}, \mathrm{B}$, and $\mathrm{C}$, the dopamine concentration in the brain appeared nearly similar with little elevation in group C. In comparison with group A, very highly significant depletion of dopamine concentrations has been detected in group $\mathrm{D}(P<0.001)$ and highly significant reduction in groups $\mathrm{E}$ and $\mathrm{F}(P<0.01)$ as in Figure 3(a).

No significant differences in the brain-serotonin concentration were detected between groups $\mathrm{A}, \mathrm{B}, \mathrm{C}$, and $\mathrm{F}$ while highly significant reduction $(P<0.01)$ and significant decrease $(P<0.05)$ have been detected in groups $\mathrm{D}$ and $\mathrm{E}$, respectively (Figure $3(\mathrm{~b})$ ).

The present acetylcholine concentrations showed similar results to dopamine. In groups $\mathrm{A}, \mathrm{B}$, and $\mathrm{C}$, its concentration did not have any insignificant differences while it displayed very highly significant $(P<0.001)$, highly significant $(P<$ $0.01)$, and significant $(P<0.05)$ depletion in groups $\mathrm{D}, \mathrm{E}$, and $\mathrm{F}$, respectively (Figure 3(c)).

3.3.2. Oxidative Stress. In comparison with control newborns, the brain lipid peroxidation was insignificantly reduced in group B while insignificant increase was observed in group C (Figure 4(a)). The elevation of TBARS was highly significant $(P<0.01)$ in group $\mathrm{D}$ and insignificant $(P>0.05)$ in groups $\mathrm{E}$ and $\mathrm{F}$ (Figure 4(a)).

$\mathrm{Cd}$ exposure produced noticeable reduction in $\mathrm{GSH}$ content $(P<0.001)$ in group $\mathrm{D}(\sim 50 \%)$. Improvement was observed in groups $\mathrm{E}$ and $\mathrm{F}$ although the difference between them and control group was still significant $(P<0.05)$ according to Figure 4(b). Insignificant difference $(P>0.05)$ was observed between groups A, B, and C (Figure 4(b)).

Peroxidase activity showed fluctuations in the experiment groups. No significant difference was observed between groups $\mathrm{A}$ and $\mathrm{C}$ while an insignificant reduction was noticed in group B. Cd exposed groups showed significant increase of peroxidase activity in both groups $\mathrm{D}$ and $\mathrm{F}$ while the increase was insignificant $(P>0.05)$ in group $\mathrm{E}$ (Figure $4(\mathrm{c}))$. The maximal elevation of peroxidase activity was observed in group $\mathrm{D}(P<0.01)$.

3.4. Brain Histoarchitecture Changes. At postnatal day 30, the normal pyramidal neurons exhibited their general characteristic shape. The nuclei of these cells were rounded, large, and centrally located (Figure 5). The normal cerebral cortex cells had pyramidal or spherical perikaryon with large nuclei where the cells were arranged in a uniform pattern (Figures 5(a), 5(b), and 5(c)). These neurons seemed more developed if we move toward the white matter. The cerebral investigation of many sections in the $\mathrm{Cd}$ exposed groups showed some pathological cases. In group D, chromatolysis and pyknosis have been observed in the pyramidal neurons. In groups $\mathrm{E}$ and F, parsley juice showed significant neuronal protection through reducing the rate of chromatolysis and pyknosis (Figures 5(d), 5(e), and 5(f)).

In the cerebellum, the fold layers (molecular, Purkinje cells, and internal granular) have become completely mature and the external granular layer disappeared completely (Figure 6). The neuronal density in the molecular layer of normal and parsley treated groups was the highest compared to Cd treated groups. The normal Purkinje cells had a pearshaped perikaryon and large nucleus and were arranged in a single row. The lateral processes disappeared and the apical processes formed the permanent dendritic tree (Figure 6). In 

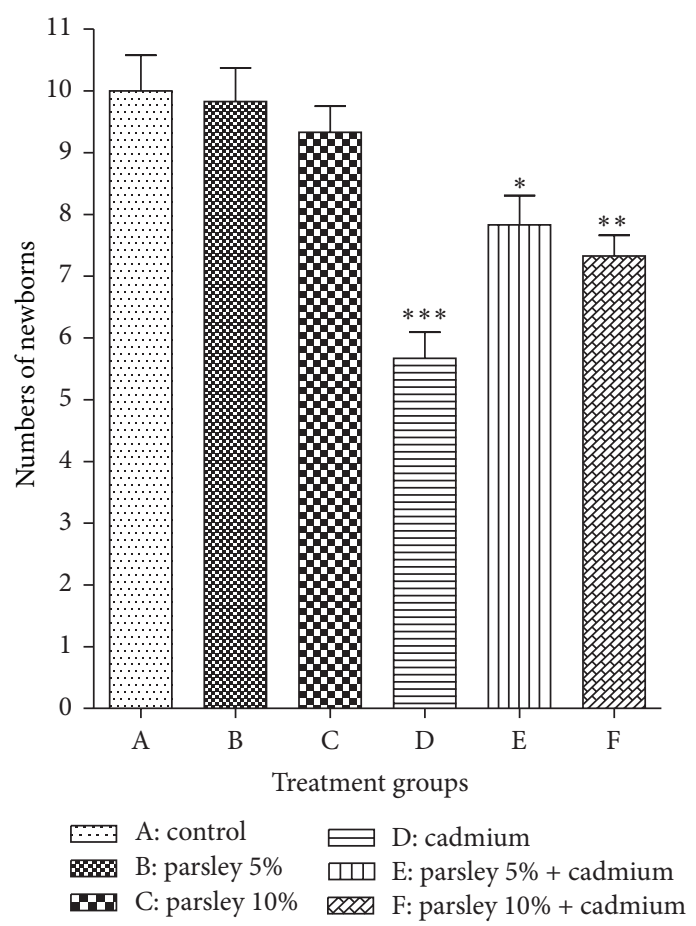

(a)

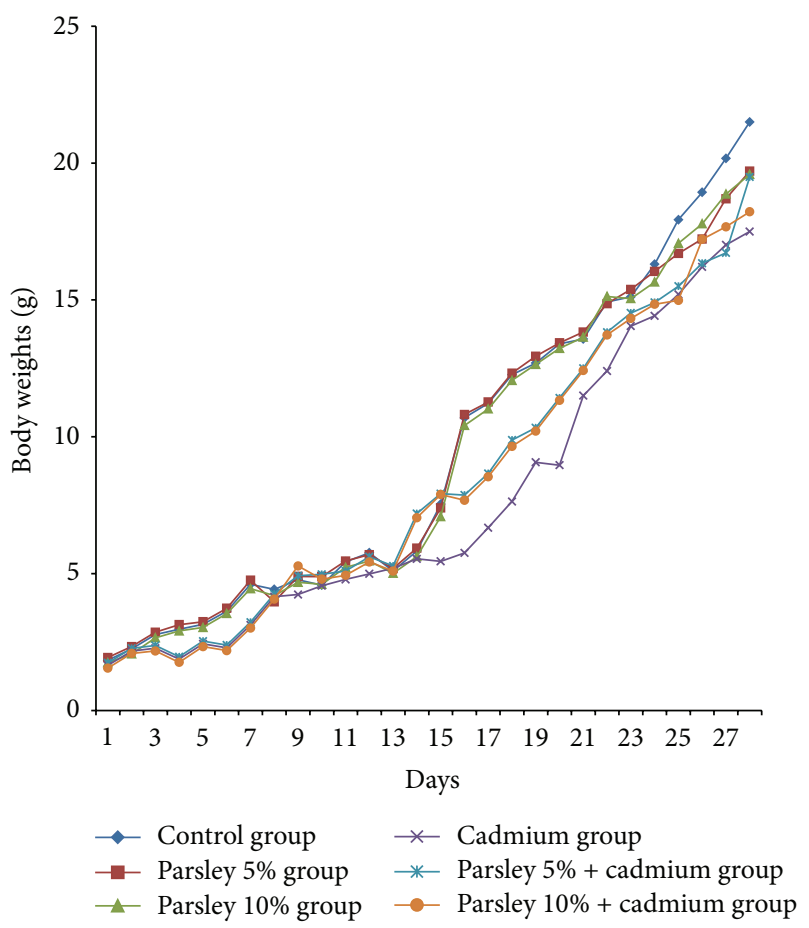

(b)

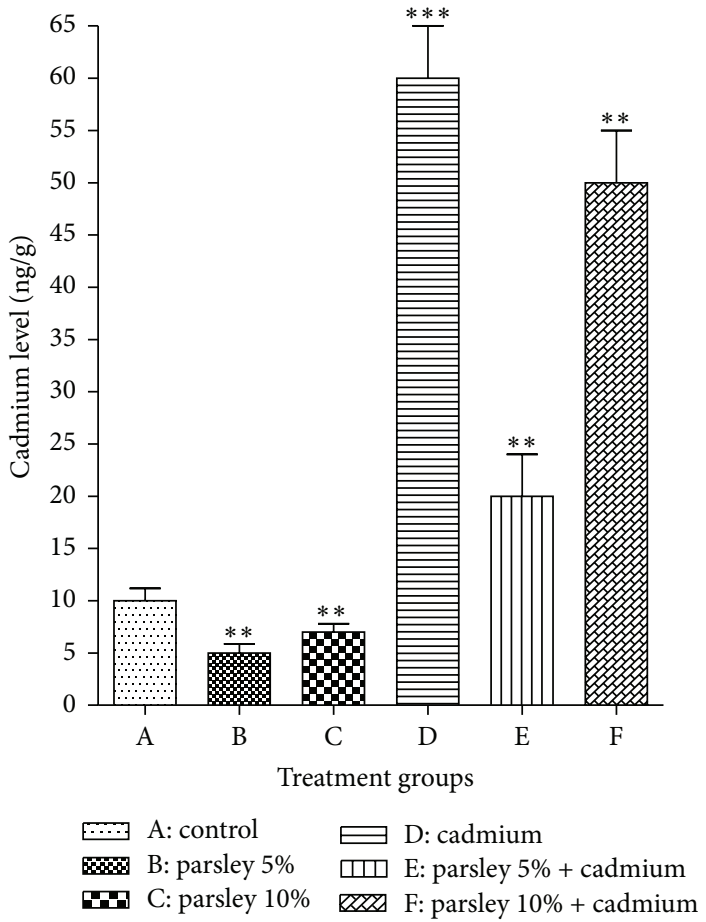

(c)

FIgURE 1: Postnatal developmental observations. (a) The number of alive delivered newborns (litter size) of each group at postnatal day 1. (b) The newborns body weights of each group from postnatal day 1 to day 28. (c) The Cd concentration in the brain tissues of the newborns of each group at postnatal day 30 . Data are expressed as mean $\pm \mathrm{SE}\left(N=6 ;{ }^{*} P<0.05,{ }^{* *} P<0.01\right.$, and ${ }^{* * *} P<0.001$, significantly different from the control group). 

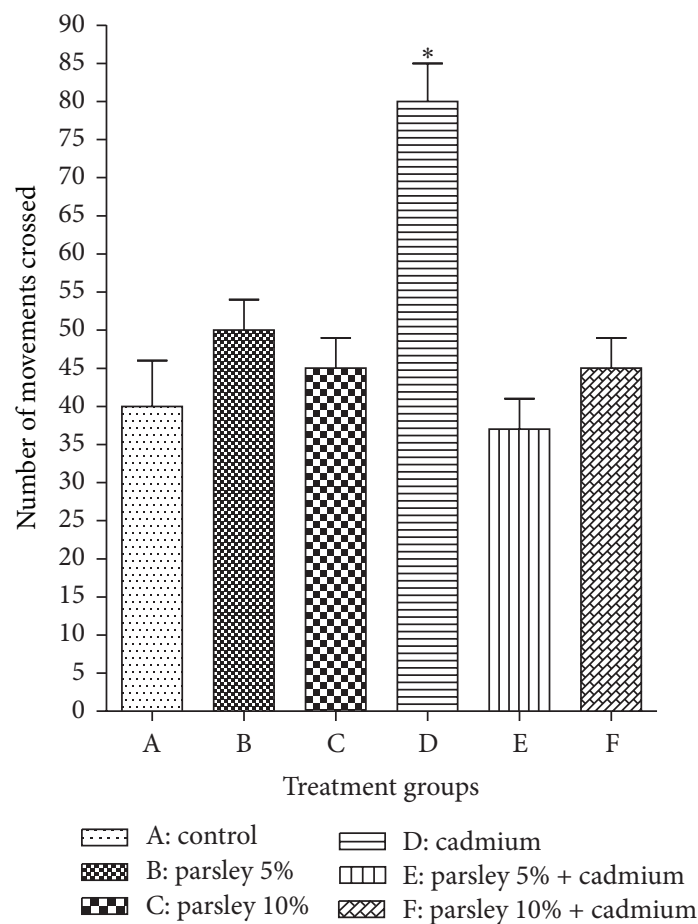

(a)
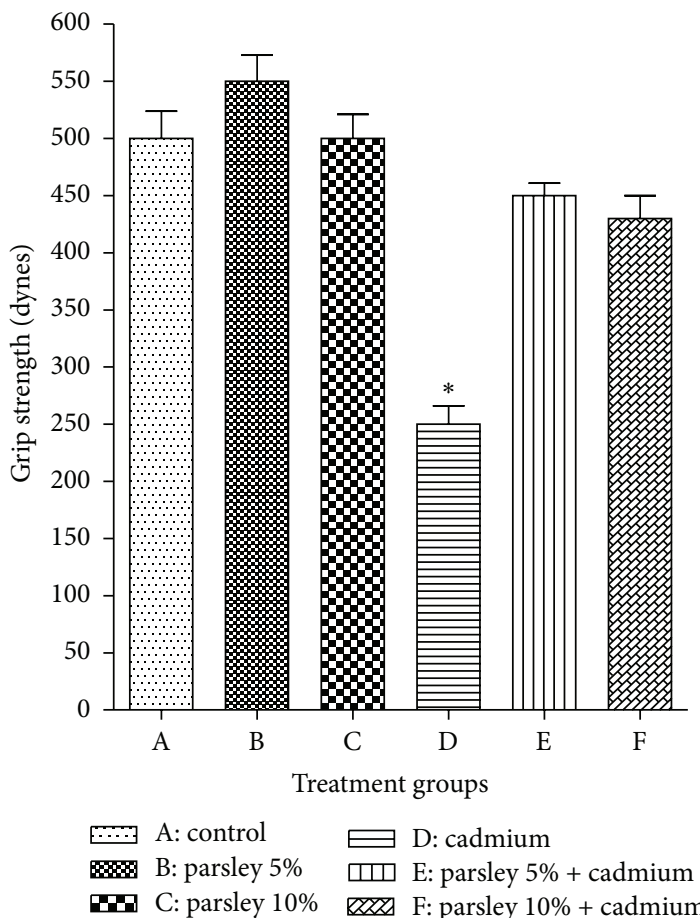

(c)
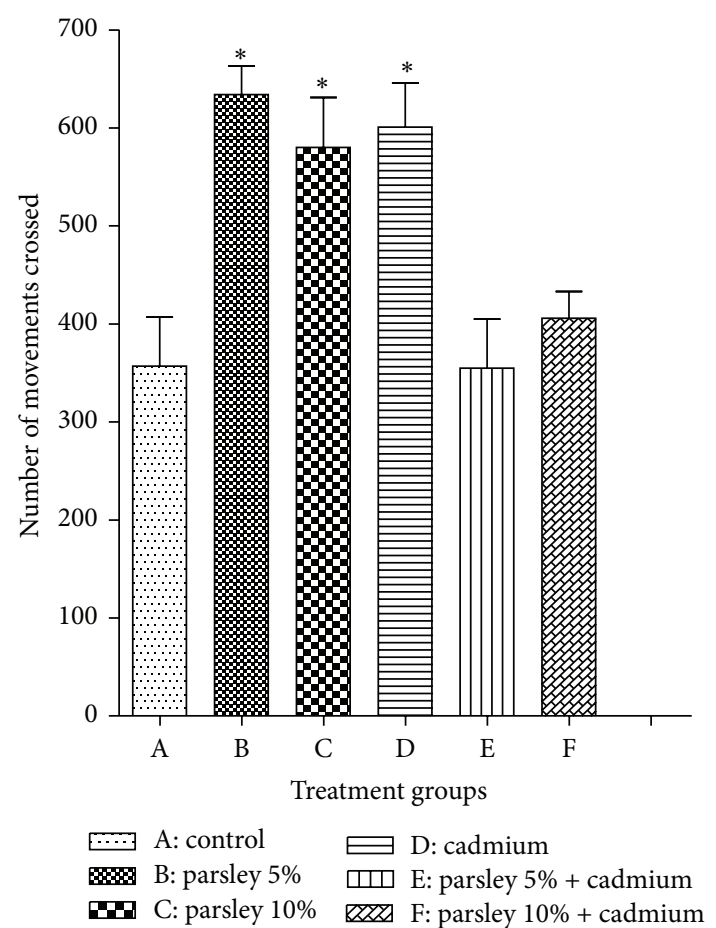

(b)
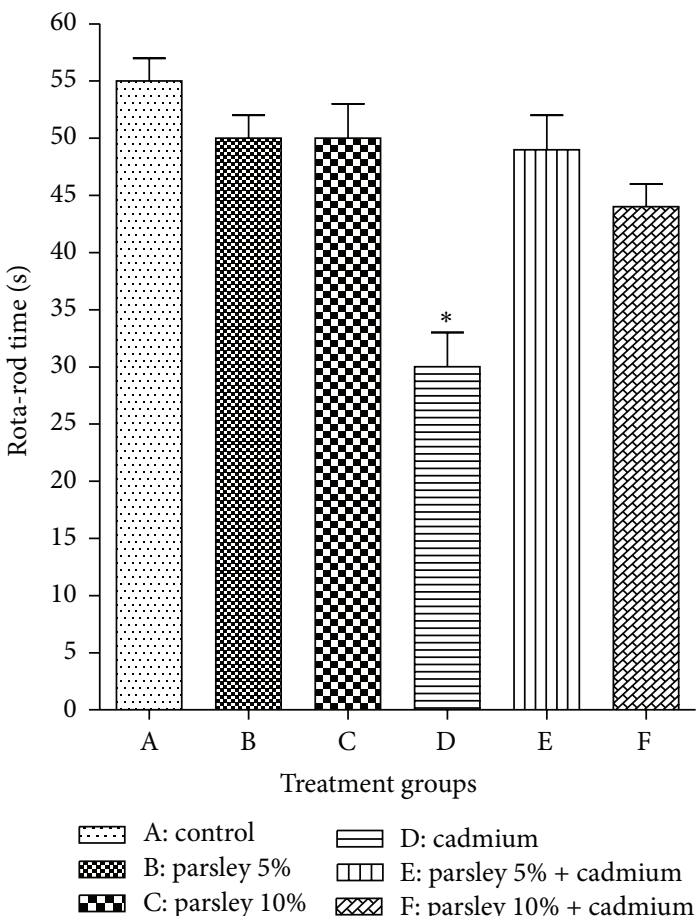

(d)

Figure 2: Behavioral investigations of the newborns of each group at D 30. (a) Vertical movements, (b) horizontal movements, (c) grip strength records for the forelimb, and (d) rota-rod records. Data are expressed as mean $\pm \mathrm{SE}\left(N=6{ }^{*} P<0.05\right.$, significantly different from the control group). 

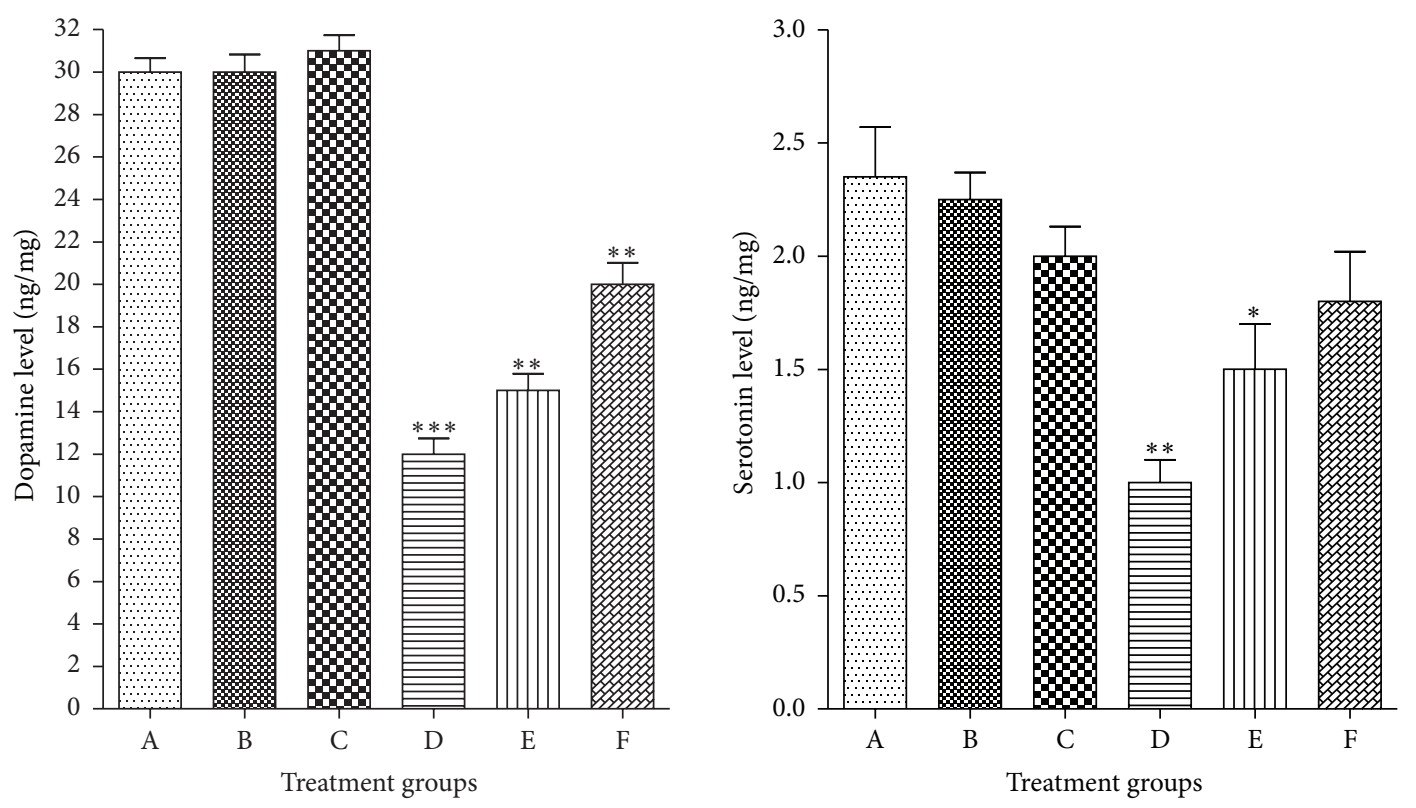

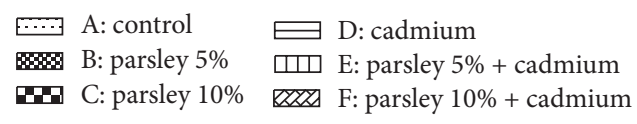

(a)

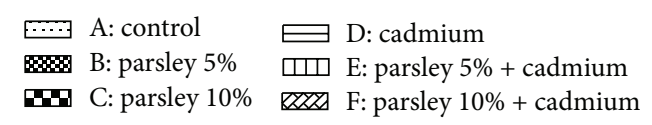

(b)

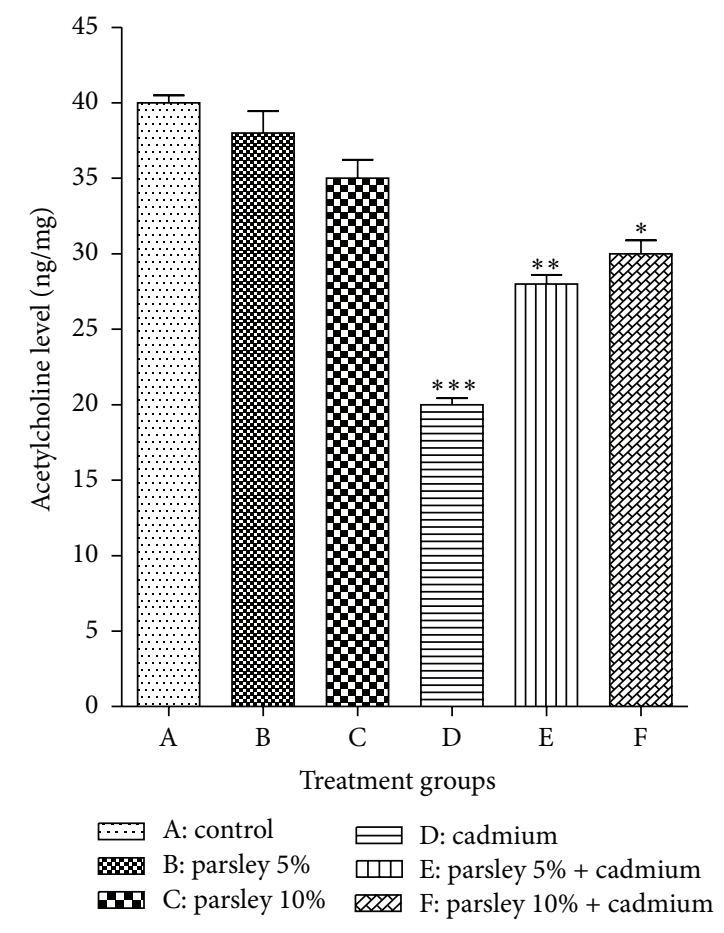

(c)

FIgURE 3: Extracellular neurotransmitters concentration in the newborns brain tissues at postnatal day 30. (a) Dopamine, (b) serotonin, and (c) acetylcholine. Data are expressed as mean $\pm \mathrm{SE}\left(N=6 ;{ }^{*} P<0.05,{ }^{* *} P<0.01\right.$, and ${ }^{* * *} P<0.001$, significantly different from the control group). 

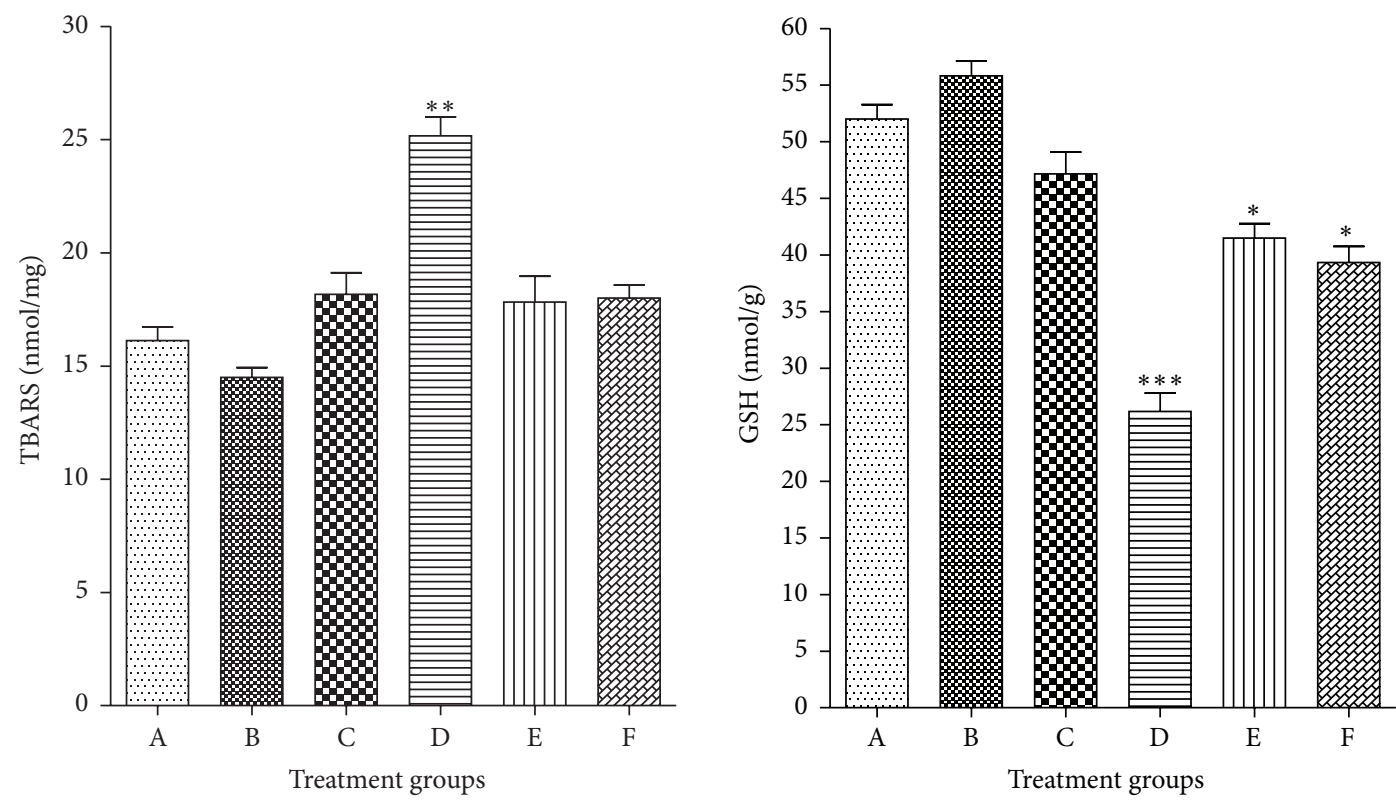

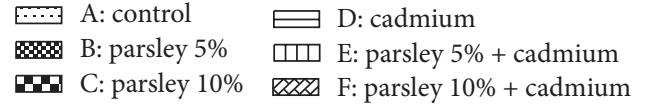

(a)

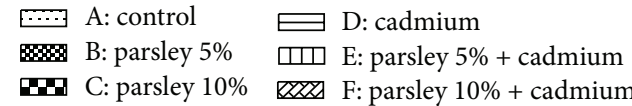

(b)

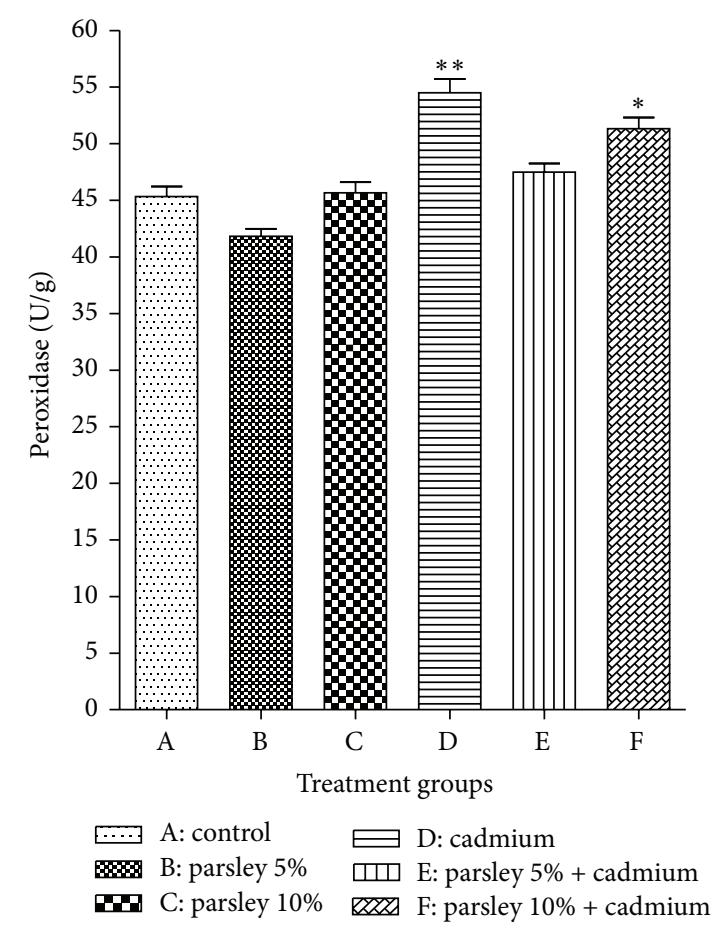

(c)

FIGURE 4: Oxidative stress parameters in the brain tissues of the newborns of each group at postnatal day 30. (a) TBARS, (b) GSH, and (c) peroxidase. Data are expressed as mean $\pm \operatorname{SE}\left(N=6 ;{ }^{*} P<0.05,{ }^{* *} P<0.01\right.$, and ${ }^{* * *} P<0.001$, significantly different from the control group). 


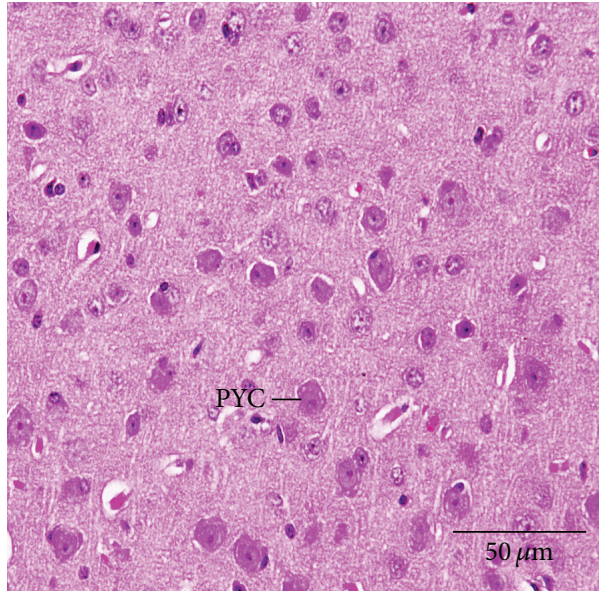

(a)

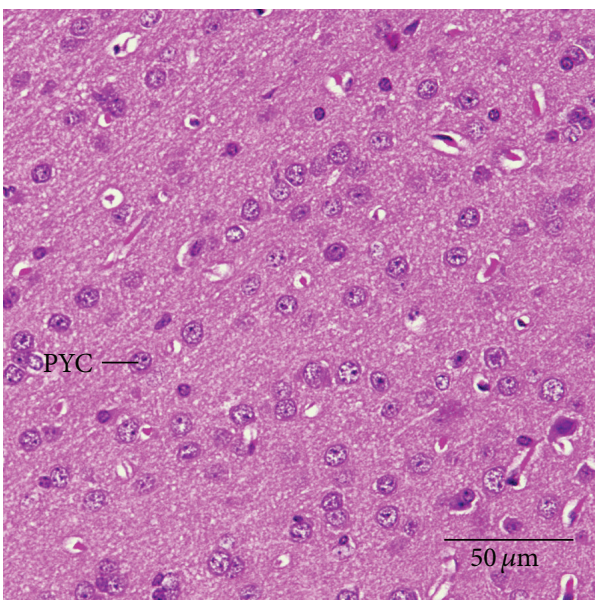

(c)

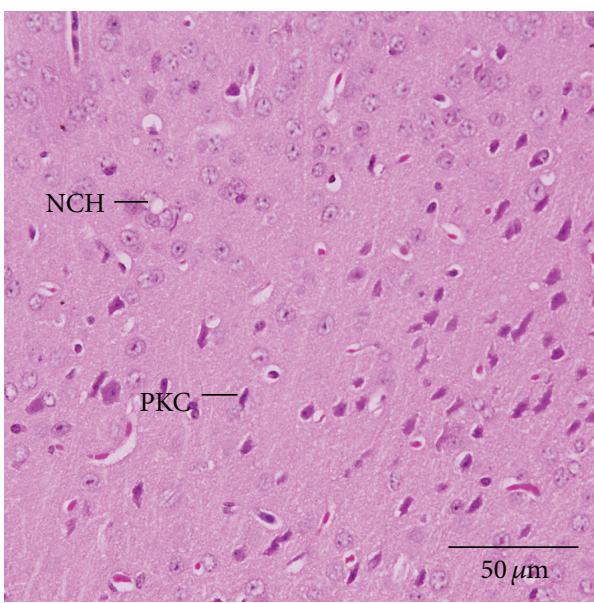

(e)

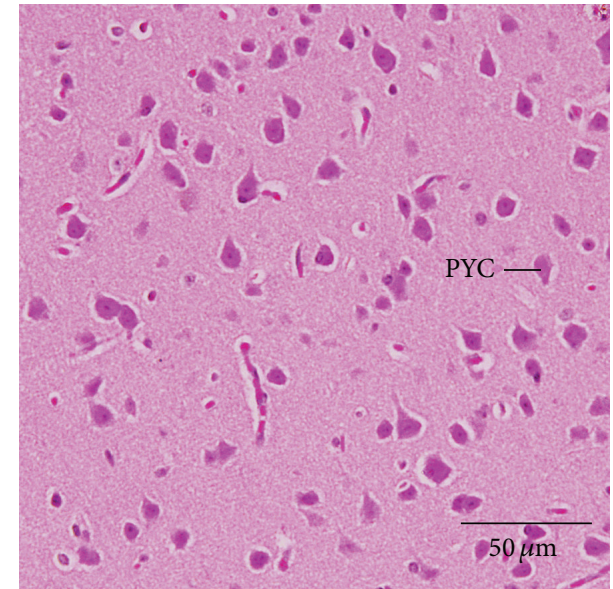

(b)

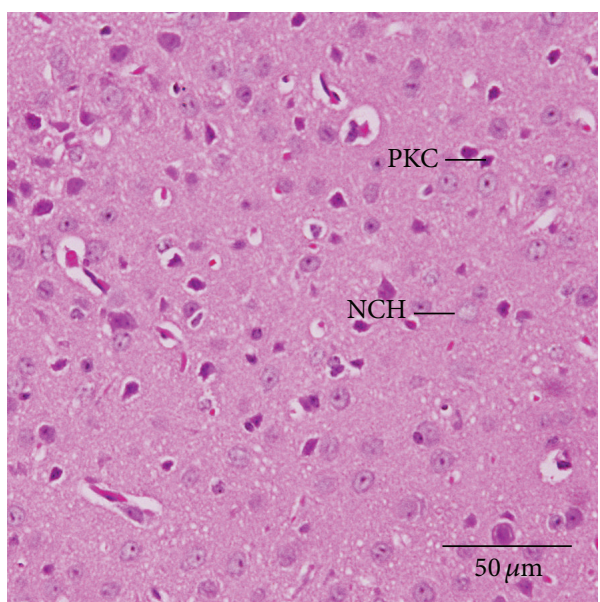

(d)

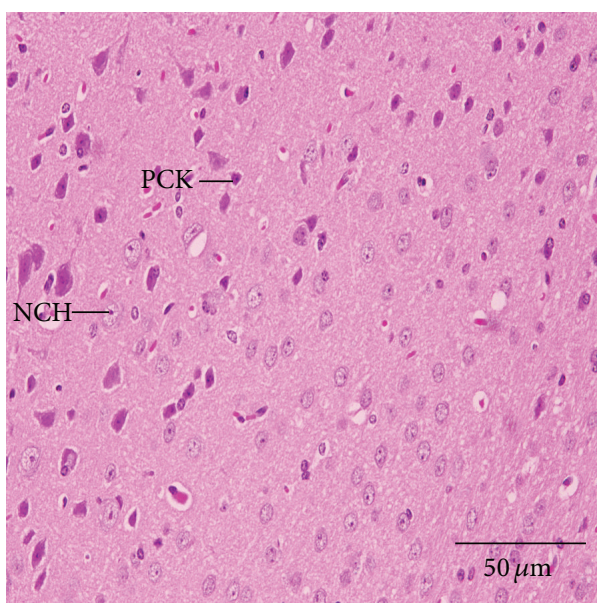

(f)

FIGURE 5: Histological changes in the cerebral cortex of the newborns at postnatal day 30 showing pyramidal neurons (PYC), degenerated pyramidal cells (PKC), and neurocyte chromatolysis ( $\mathrm{NCH}$ ). (a) Control group, (b) parsley 5\% group, (c) parsley $10 \%$, (d) cadmium inoculated group, (e) cadmium inoculated group + parsley 5\%, and (f) cadmium inoculated group + parsley 5\% (H\&E stain). 


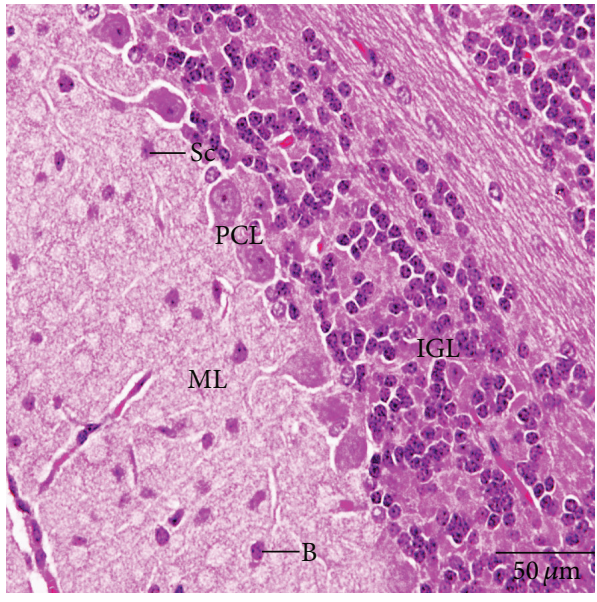

(a)

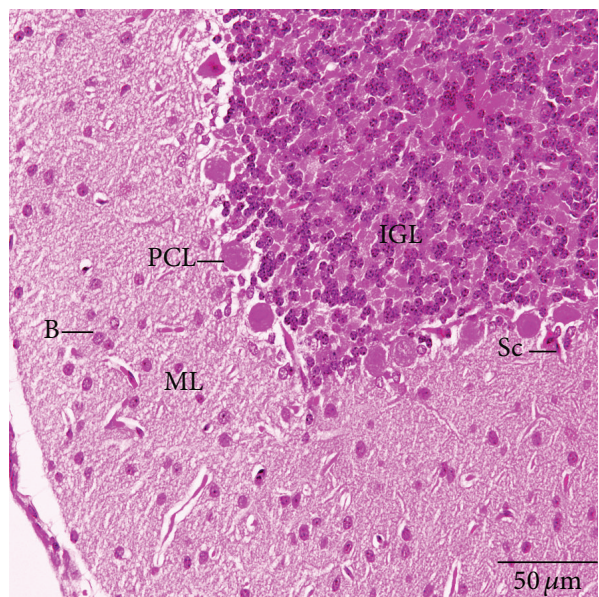

(c)

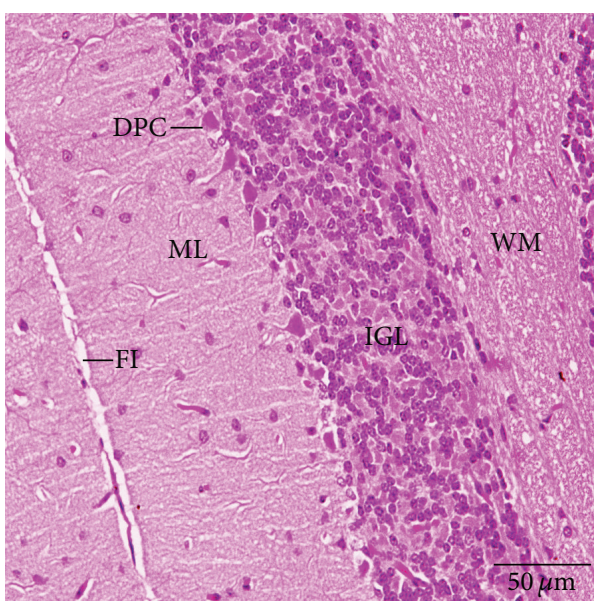

(e)

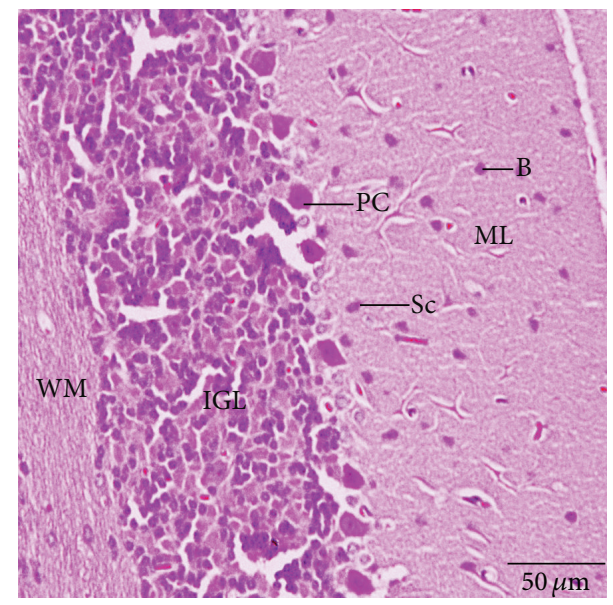

(b)

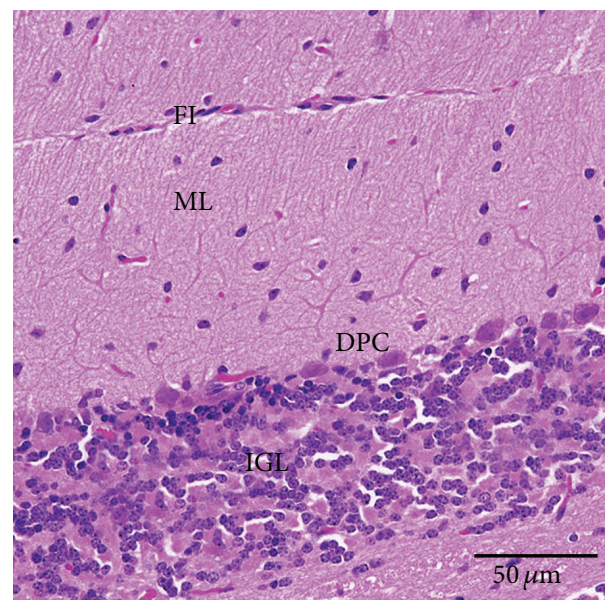

(d)

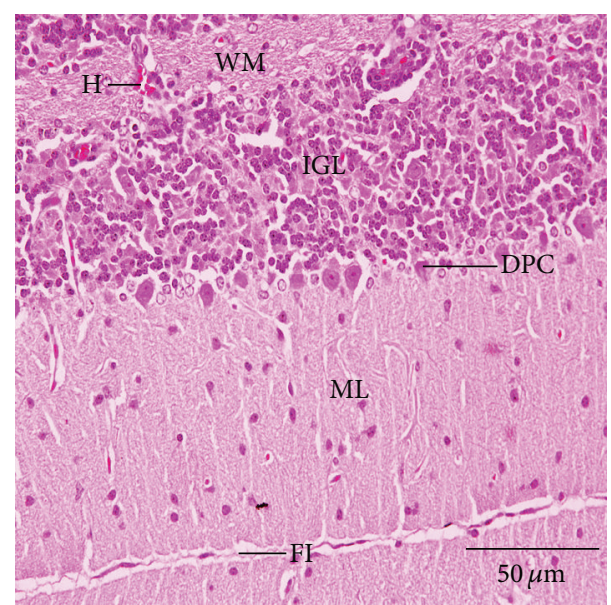

(f)

Figure 6: Histological changes in the cerebellar cortex of the newborns at postnatal day 30 showing Purkinje cell (PC), Purkinje cell layer (PCL), degenerated Purkinje cell (DPC), fissure (FI), hemorrhage (H), internal granular layer (IGL), molecular layer (ML), and white matter (WM). (a) Control group, (b) parsley 5\% group, (c) parsley 10\%, (d) cadmium inoculated group, (e) cadmium inoculated group + parsley 5\%, and (f) cadmium inoculated group + parsley $5 \%$ (H\&E stain). 
Cd treated groups, some pyknotic and degenerated Purkinje cells were observed and some were more spindle-shaped and small. These numbers of degenerated Purkinje neurons reduced in groups E and F (Figures 6(d), 6(e), and 6(f)). Variations have been observed in the folds size of the groups where small folds appeared in group D.

The normal medulla neurons appeared to be large in size, polygonal, and varied in shape and had round nuclei (Figures 7(a), 7(b), and 7(c)). In Cd treated group, most of medulla neurons appeared small and pyknotic (Figure 6(d)). Cd-parsley treated groups medulla neurons showed improvement (Figures 6(e) and 6(f)).

\section{Discussion}

The current study has been designed to investigate the protective role of parsley juice against $\mathrm{Cd}$ teratogenicity in albino mouse newborns. These results proposed that the intake of parsley may improve the malformations due to exposure of female pregnant mice to $\mathrm{Cd}$. The effect of daily supplementation of the two different doses of parsley on the deleterious changes of $\mathrm{Cd}$ in litter size, pups body weight, behavioral activities, brain neurotransmitters, brain oxidative stress, brain Cd concentration, and brain histoarchitecture was discussed in the current study. The small litter size of the nonprotected $\mathrm{Cd}$ treated group shows the hazardous effect of $\mathrm{Cd}$ on pregnancy. Antonio et al. [14] recorded that prenatal $\mathrm{Cd}$ exposures induce fetal resorption and abortion. Cd passes through placenta and is dispensed in the embryos tissues during pregnancy [11]. The high accumulation of $\mathrm{Cd}$ in brain tissues of Cd treated groups due to prenatal and postnatal passing through placenta and mother's milk to its newborns as reported early by Shaheed et al. [45]. The low concentration of $\mathrm{Cd}$ in the pup's brain tissue in groups $\mathrm{E}$ and $\mathrm{F}$ may be explained by the ability of the mothers of these two groups to get off the administrated $\mathrm{Cd}$ due to the ingested parsley.

The current results reported that the Cd exposed groups showed reeducation in the pup's body weights as reported in earlier studies. The reasons this weight loss may be prenatal due to intrauterine $\mathrm{Cd}$ exposures that produce growth deficiency for the developed fetus or postnatal as maternal Cd exposure causes bad lactation due to maternal bad behaviors caused also by $\mathrm{Cd}$ and consequently leads to postnatal malnutrition fort the neonates [45]. In addition, Friedman et al. [46] confirmed the main reason for the postnatal pup's weight loss because they culminate from maternal behaviors alterations in $\mathrm{Cd}$ exposed groups as well as a decrease in the lactation index. Pups body weights are the most sensitive indicator of developmental toxicity [47]. The results of groups $\mathrm{E}$ and $\mathrm{F}$ showed that parsley juice has an observable protective effect against $\mathrm{Cd}$ accumulation and prenatal effects, especially the low dose. These may be due to the significant effect of parsley in the excretion of heavy metals such as $\mathrm{Cd}$ from mother's bodies so the complications of Cd toxicity reduced and disappeared in the pups of parsley ingested groups [27].

The present levels of the neurotransmitters were depleted significantly by $\mathrm{Cd}$ treatment in the brain tissue of the $\mathrm{Cd}$ exposed groups. The inhibition of dopamine, serotonin, and acetylcholine occurs in depressing the hyperexcitability of brain neurons as what appeared by the poor performance of the treated pups in the current behavioral examinations [3]. Recently, a growing body of research has focused on the participation of serotonin in the neurochemical mechanisms of cognition and especially of learning and memory. Potential toxic mechanisms of action for $\mathrm{Cd}$ may include disruption in serotonergic neurotransmission through disturbed levels of neurotransmitters in the brain [3]. It was mentioned before that $\mathrm{Cd}$ toxicity disrupts the action of the acetylcholine esterase activity, so the sensorimotor performances of the newborns will be affected [9]. The disturbances in the levels of current neurotransmitters levels in the toxicity exposed groups may be due to the impact of $\mathrm{Cd}$ on the neurons functions [3], while the improvements in the parsley juice ingested groups may be because the ability of this component to limit the Cd impacts the neurons.

Although groups $\mathrm{D}, \mathrm{E}$, and $\mathrm{F}$ pups were exposed to $\mathrm{Cd}$ perinatally (during gestation and lactation), group $\mathrm{D}$ displayed a marked elevation in the oxidative stress and a depletion of the antioxidants, compared to groups $\mathrm{E}$ and $\mathrm{F}$. One aspect of the oxidative stress elevation was the significant increase of the lipid peroxidation in group D. MéndezArmenta and Ríos [15] reported that the lipid peroxidation and TBARS increased after acute Cd toxicity. Glutathione is one of the most important compounds for the preserve of cell integrity because of its reducing ability and participation in the cell metabolism as well as a well sensitive reflector of the oxidative stress state in laboratory animals and human [48].

It was observed in many oxidative stress states that the reduction of GSH induces the elevation of lipid peroxidation. Therefore, GSH is an important indicator and biomarker of oxidative stress $[49,50]$. Almost the level of GSH is regulated by glutathione reductase (GR) which is a NADPH dependent enzyme. Therefore the limitation in active GR and NADPH may adversely affect GSH levels [50]. Furthermore, interaction of electrophilic xenobiotics such as heavy $\mathrm{Cd}$ and its metabolites products with GSH forms glutathione-S conjugates which deplete GSH concentrations in the tissue cells [40, 51]. Abu-Taweel et al. [3] reported that Cd exposure depleted GSH content and elevates peroxidase enzymes activities in adult mice. Increasing of peroxidase activity may be due to the presence of generated free radicals [52]. Peroxidases are considered as one of the antioxidant enzymes which constitute a mutually supportive defense team against free radicals such as reactive oxygen species (ROS) as mentioned by Allam et al. [50].

Several mechanisms may explain the reasons of oxidative stress increasing due to heavy metals toxicity, especially the chronic toxicity. For example, the chronic Cd inhalation leads to Cd accumulation which elevates ROS and reactive nitrogen species (RNS) production by the mitochondrial respiratory system. This will exhaust the antioxidant enzymes and an imbalance of glutathione redox status will be produced [7]. At altitude concentration, ROS/RNS will damage the components of the cell including nucleic acids, proteins, amino acids, and lipids [53]. Such oxidative modifications affect several cell metabolic reactions, functions, and gene 


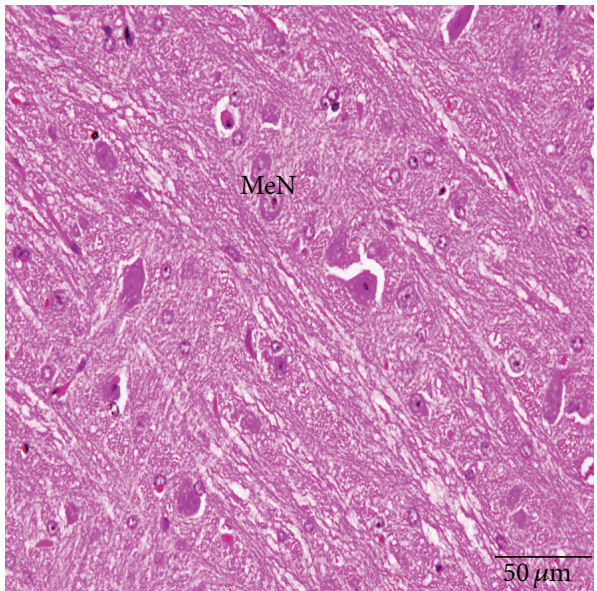

(a)

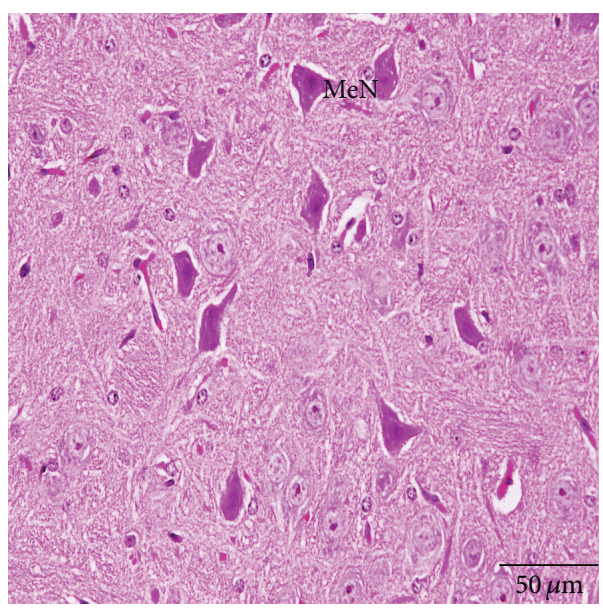

(c)

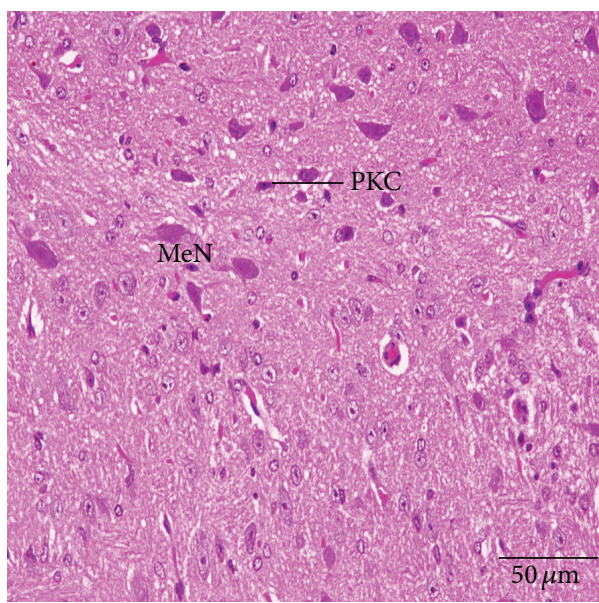

(e)

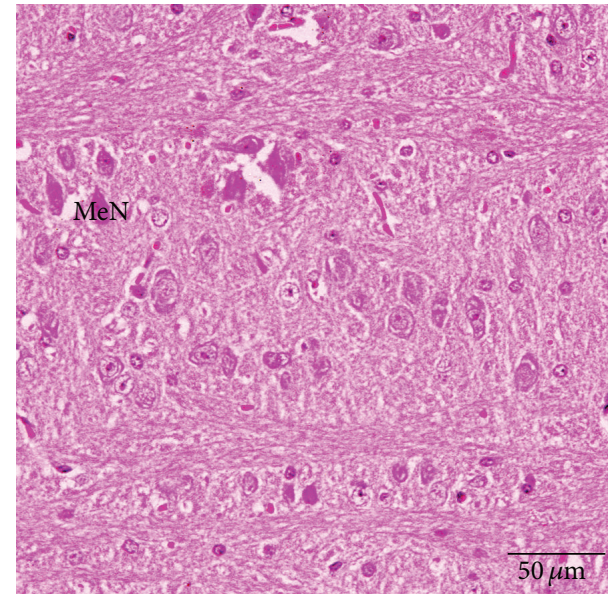

(b)

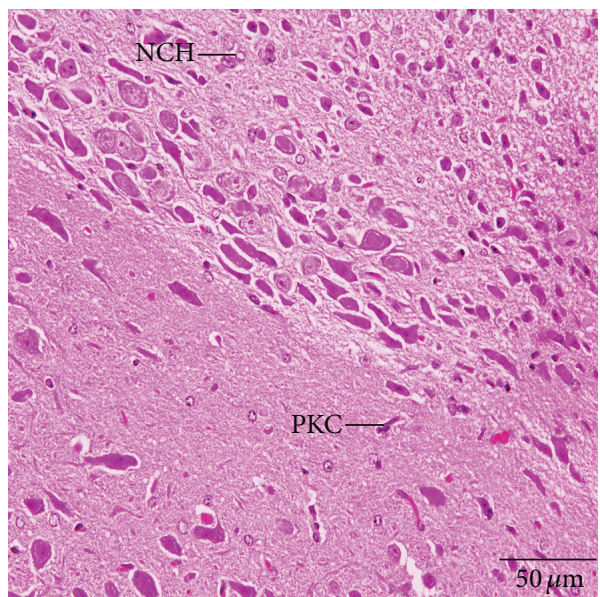

(d)

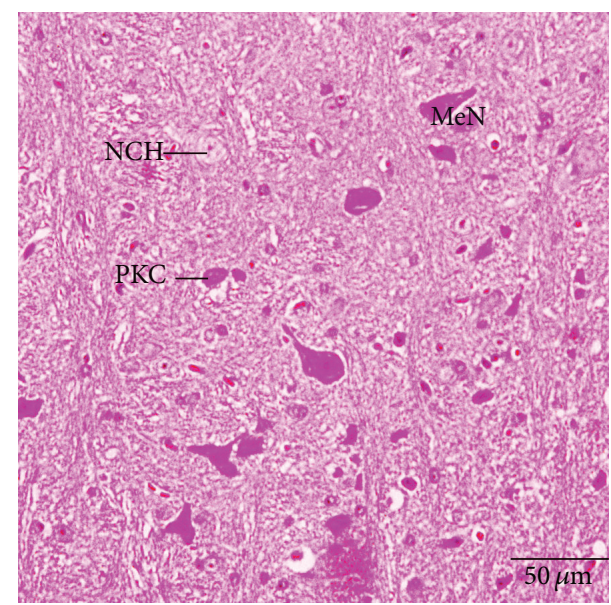

(f)

FIGURE 7: Histological changes in the medulla oblongata of the newborns at postnatal day 30 showing medulla neurons (MeN), degenerated medullary cells (PKC), and neurocyte chromatolysis ( $\mathrm{NCH}$ ). (a) Control group, (b) parsley $5 \%$ group, (c) parsley 10\%, (d) cadmium inoculated group, (e) cadmium inoculated group + parsley 5\%, and (f) cadmium inoculated group + parsley 5\% (H\&E stain). 
expression which in turn can cause other pathological conditions [54]. The oxidative stress leads to neuronal damage in several brain regions $[40,49,55]$. For example, neuronal loss in cerebrum impairs animal's memory [38], neuronal loss in cerebellum can have effect on balance and coordination [40], and neuronal loss in medulla oblongata and spinal cord can affect physical activity of mice [56].

Phytochemical screening of parsley has revealed the presence of some compounds such as flavonoids [19], carotenoids [20], ascorbic acid [21], and tocopherol [22]. These components of fresh parsley leaf scavenge superoxide anion in vitro and hydroxyl radical in addition to protecting against ascorbic acid-induced membrane oxidation [19]. Supplementation with parsley juice for 50 days prevent to somewhat the $\mathrm{Cd}$ toxicity showed significant improvement in the physical balance, coordination, motor activities, muscles strength, and brain neurotransmitters levels in $\mathrm{Cd}$ treated pups of groups E and F. Parsley supplement also restored GSH balance and decreased lipid peroxidation and peroxidase activity. Overall, this study demonstrated that low dose of parsley supplementation significantly improved pathological alterations in mice as reported by Zhang et al. [30]. Parsley juice components were found to be significant suppressors to $\mathrm{H}_{2} \mathrm{O}_{2}$ and ROS levels in brain and other tissues in mice by stimulating production of glutathione synthesis and thereby boosting cellular antioxidant defense [30]. Therefore, we suggest that parsley may be an important therapeutic tool to combat oxidative stress-associated diseases. We propose that diluted parsley juice may ameliorate $\mathrm{Cd}$ neurotoxicity complications in mice by its ability to neutralize free radicals and thereby prevent neuronal damage caused by oxidative stress.

\section{Conclusion}

Parsley has a protective effect against Cd neurotoxicity and teratogenicity in albino mice. Parsley juice supplementation improves the behavior of perinatally $\mathrm{Cd}$ intoxicated mice newborns and reduces neuronal aberrations in the brain caused by oxidative stress.

\section{Conflict of Interests}

The authors declare that they have no competing or conflict of interests.

\section{Acknowledgment}

The authors would like to extend their sincere appreciation to the Deanship of Scientific Research at King Saud University for its funding of this research through Research Group Project no. RGP-VPP-240.

\section{References}

[1] B. A. Fowler, "Monitoring of human populations for early markers of cadmium toxicity: a review," Toxicology and Applied Pharmacology, vol. 238, no. 3, pp. 294-300, 2009.
[2] V. Matović, A. Buha, Z. Bulat, and D. Đukić-Ćosić, "Cadmium toxicity revisited: focus on oxidative stress induction and interactions with zinc and magnesium," Archives of Industrial Hygiene and Toxicology, vol. 62, no. 1, pp. 65-76, 2011.

[3] G. M. Abu-Taweel, J. S. Ajarem, and M. Ahmad, "Protective effect of curcumin on anxiety, learning behavior, neuromuscular activities, brain neurotransmitters and oxidative stress enzymes in cadmium intoxicated mice," Journal of Behavioral and Brain Science, vol. 3, no. 1, pp. 74-84, 2013.

[4] M. M. Brzóska, K. Majewska, and E. Kupraszewicz, "Effects of low, moderate and relatively high chronic exposure to cadmium on long bones susceptibility to fractures in male rats," Environmental Toxicology and Pharmacology, vol. 29, no. 3, pp. 235-245, 2010.

[5] F. D. S. Predes, M. A. S. Diamante, and H. Dolder, "Testis response to low doses of cadmium in Wistar rats," International Journal of Experimental Pathology, vol. 91, no. 2, pp. 125-131, 2010.

[6] L. C. Xu, H. Sun, S. Y. Wang et al., "The roles of metallothionein on cadmium-induced testes damages in Sprague-Dawley rats," Environmental Toxicology and Pharmacology, vol. 20, no. 1, pp. 83-87, 2005.

[7] S. Haider, L. Anis, Z. Batool et al., "Short term cadmium administration dose dependently elicits immediate biochemical, neurochemical and neurobehavioral dysfunction in male rats," Metabolic Brain Disease, vol. 30, no. 1, pp. 83-92, 2015.

[8] S. G. Terçariol, A. A. Almeida, and A. F. Godinho, "Cadmium and exposure to stress increase aggressive behavior," Environmental Toxicology and Pharmacology, vol. 32, no. 1, pp. 40-45, 2011.

[9] J. F. Gonçalves, A. M. Fiorenza, R. M. Spanevello et al., " $\mathrm{N}$-acetylcysteine prevents memory deficits, the decrease in acetylcholinesterase activity and oxidative stress in rats exposed to cadmium," Chemico-Biological Interactions, vol. 186, no. 1, pp. 53-60, 2010.

[10] H. Soreq and S. Seidman, "Acetylcholinesterase-new roles for an old actor," Nature Reviews Neuroscience, vol. 2, no. 4, pp. 294302, 2001.

[11] J. F. Gonçalves, F. T. Nicoloso, P. da Costa et al., "Behavior and brain enzymatic changes after long-term intoxication with cadmium salt or contaminated potatoes," Food and Chemical Toxicology, vol. 50, no. 10, pp. 3709-3718, 2012.

[12] L. Y. Zhang, W. W. Zhang, D. Cao et al., "Effect of heavy metalsolubilizing microorganisms on zinc and cadmium extractions from heavy metal contaminated soil with Tricholoma lobynsis," World Journal of Microbiology and Biotechnology, vol. 28, no. 1, pp. 293-301, 2012.

[13] Z. Wang, H. Wang, Z. M. Xu et al., "Cadmium-induced teratogenicity: association with ROS-mediated endoplasmic reticulum stress in placenta," Toxicology and Applied Pharmacology, vol. 259, no. 2, pp. 236-247, 2012.

[14] M. T. Antonio, N. López, and M. L. Leret, "Pb and Cd poisoning during development alters cerebellar and striatal function in rats," Toxicology, vol. 176, no. 1-2, pp. 59-66, 2002.

[15] M. Méndez-Armenta and C. Ríos, "Cadmium neurotoxicity," Environmental Toxicology and Pharmacology, vol. 23, no. 3, pp. 350-358, 2007.

[16] S. J. Stohs, D. Bagchi, E. Hassoun, and M. Bagchi, "Oxidative mechanism in the toxicity of chromium and cadmium ions," Journal of Environmental Pathology, Toxicology and Oncology, vol. 19, no. 3, pp. 201-213, 2000. 
[17] I. Jaswir, Y. B. Che Man, and D. D. Kitts, "Synergistic effects of rosemary, sage, and citric acid on fatty acid retention of palm olein during deep-fat frying," JAOCS, Journal of the American Oil Chemists' Society, vol. 77, no. 5, pp. 527-533, 2000.

[18] Q. Zhai, A. Narbad, and W. Chen, "Dietary strategies for the treatment of cadmium and lead toxicity," Nutrients, vol. 7, no. 1, pp. 552-571, 2015.

[19] S. Fejes, A. Blázovics, É. Lemberkovics, G. Petri, É. Szöke, and Á. Kéry, "Free radical scavenging and membrane protective effects of methanol extracted fractions of parsley," Acta Alimentaria, vol. 29, no. 1, pp. 81-87, 2000.

[20] D. Gadi, M. Bnouham, M. Aziz et al., "Parsley extract inhibits in vitro and ex vivo platelet aggregation and prolongs bleeding time in rats," Journal of Ethnopharmacology, vol. 125, no. 1, pp. 170-174, 2009.

[21] M. W. Davey, G. Bauw, and M. V. Montagu, "Analysis of ascorbate in plant tissues by high-performance capillary zone electrophoresis," Analytical Biochemistry, vol. 239, no. 1, pp. 819, 1996.

[22] S. Fiad and M. El Hamidi, "Vitamin E and trace elements," Seifen, Oele, Fette, Wachse, vol. 119, pp. 25-26, 1993.

[23] S. E. Nielsen, J. F. Young, B. Daneshvar et al., "Effect of parsley (Petroselinum crispum) intake on urinary apigenin excretion, blood antioxidant enzymes and biomarkers for oxidative stress in human subjects," British Journal of Nutrition, vol. 81, no. 6, pp. 447-455, 1999.

[24] P. Y. Y. Wong and D. D. Kitts, "Studies on the dual antioxidant and antibacterial properties of parsley (Petroselinum crispum) and cilantro (Coriandrum sativum) extracts," Food Chemistry, vol. 97, no. 3, pp. 505-515, 2006.

[25] M. Eddouks, M. Maghrani, A. Lemhadri, M.-L. Ouahidi, and H. Jouad, "Ethnopharmacological survey of medicinal plants used for the treatment of diabetes mellitus, hypertension and cardiac diseases in the south-east region of Morocco (Tafilalet)," Journal of Ethnopharmacology, vol. 82, no. 2-3, pp. 97-103, 2002.

[26] H. Jouad, M. Haloui, H. Rhiouani, J. El Hilaly, and M. Eddouks, "Ethnobotanical survey of medicinal plants used for the treatment of diabetes, cardiac and renal diseases in the North centre region of Morocco (Fez-Boulemane)," Journal of Ethnopharmacology, vol. 77, no. 2-3, pp. 175-182, 2001.

[27] V. Darias, D. Martín-Herrera, S. Abdala, and D. Dela Fuente, "Plants used in urinary pathologies in the Canary Islands," Pharmaceutical Biology, vol. 39, no. 3, pp. 170-180, 2001.

[28] R. Yanardağ, Ş. Bolkent, A. Tabakoğlu-Oğuz, and Ö. ÖzsoySaçan, "Effects of Petroselinum crispum extract on pancreatic B cells and blood glucose of streptozotocin-induced diabetic rats," Biological and Pharmaceutical Bulletin, vol. 26, no. 8, pp. 12061210, 2003.

[29] A. Yazicioglu and E. Tuzlaci, "Folk medicinal plants of Trabzon (Turkey)," Fitoterapia, vol. 67, no. 4, pp. 307-318, 1996.

[30] H. Zhang, F. Chen, X. Wang, and H.-Y. Yao, "Evaluation of antioxidant activity of parsley (Petroselinum crispum) essential oil and identification of its antioxidant constituents," Food Research International, vol. 39, no. 8, pp. 833-839, 2006.

[31] T. Ojala, S. Remes, P. Haansuu et al., "Antimicrobial activity of some coumarin containing herbal plants growing in Finland," Journal of Ethnopharmacology, vol. 73, no. 1-2, pp. 299-305, 2000.

[32] S. I. Kreydiyyeh, J. Usta, I. Kaouk, and R. Al-Sadi, "The mechanism underlying the laxative properties of parsley extract," Phytomedicine, vol. 8, no. 5, pp. 382-388, 2001.
[33] A. M. Jassim, "Protective effect of Petroselinum crispum (parsley) extract on histopathological changes in liver, kidney and pancreas induced by sodium valproate-in male rats," Kufa Journal For Veterinary Medical Sciences, vol. 4, no. 1, pp. 20-27, 2013.

[34] M. M. Manderfeld, H. W. Schafer, P. M. Davidson, and E. A. Zottola, "Isolation and identification of antimicrobial furocoumarins from parsley," Journal of Food Protection, vol. 60, no. 1, pp. 72-77, 1997.

[35] A. Shah, A. Niaz, N. Ullah et al., "Comparative study of heavy metals in soil and selected medicinal plants," Journal of Chemistry, vol. 2013, Article ID 621265, 5 pages, 2013.

[36] J. S. Ajarem and M. Ahmad, "Behavioral and biochemical consequences of perinatal exposure of mice to instant coffee: a correlative evaluation," Pharmacology, Biochemistry and Behavior, vol. 40, no. 4, pp. 847-852, 1991.

[37] P. O. Eghwrudjakpor, H. Miyake, M. Kurisaka, and K. Mori, "Central nervous system bioaminergic responses to mechanical trauma: an experimental study," Surgical Neurology, vol. 35, no. 4, pp. 273-279, 1991.

[38] G. M. Abu-Taweel, J. S. Ajarem, and M. Ahmad, "Neurobehavioral toxic effects of perinatal oral exposure to aluminum on the developmental motor reflexes, learning, memory and brain neurotransmitters of mice offspring," Pharmacology Biochemistry and Behavior, vol. 101, no. 1, pp. 49-56, 2012.

[39] J. Ichikawa, Z. Li, J. Dai, and H. Y. Meltzer, "Atypical antipsychotic drugs, quetiapine, iloperidone, and melperone, preferentially increase dopamine and acetylcholine release in rat medial prefrontal cortex: role of 5-HT1A receptor agonism," Brain Research, vol. 956, no. 2, pp. 349-357, 2002.

[40] H. G. Preuss, S. T. Jarrell, R. Scheckenbach, S. Lieberman, and R. A. Anderson, "Comparative effects of chromium, vanadium and gymnema sylvestre on sugar-induced blood pressure elevations in SHR," Journal of the American College of Nutrition, vol. 17, no. 2, pp. 116-123, 1998.

[41] E. Beutler, O. Duron, and B. M. Kelly, "Improved method for the determination of blood glutathione," The Journal of Laboratory and Clinical Medicine, vol. 61, pp. 882-888, 1963.

[42] A. A. Allam, A. A. El-Ghareeb, M. Abdul-Hamid, A. Baikry, and M. I. Sabri, "Prenatal and perinatal acrylamide disrupts the development of cerebellum in rat: biochemical and morphological studies," Toxicology and Industrial Health, vol. 27, no. 4, pp. 291-306, 2011.

[43] M. Kar and D. Mishra, "Catalase, peroxidase, and polyphenoloxidase activities during rice leaf senescence," Plant Physiology, vol. 57, no. 2, pp. 315-319, 1976.

[44] F. B. Mallory, Pathological Techénique, WB, Saunders, Philadelphia, Pa, USA, 1988.

[45] I. B. Shaheed, A. A. Kawkab, and M. M. Makhlouf, "Toxicological and pathological studies on acrylamide neurotoxicity in albino rats," Egyptian Journal of Comparative Pathology and Clinical Pathology, vol. 19, no. 1, pp. 63-82, 2006.

[46] M. A. Friedman, R. W. Tylb, M. C. Marr, C. B. Myers, F. S. Gerling, and W. P. Ross, "Effects of lactational administration of acrylamide on rat dams and offspring," Reproductive Toxicology, vol. 13, no. 6, pp. 511-520, 1999.

[47] L. D. Wise, L. R. Gordon, K. A. Soper, D. M. Duchai, and R. E. Morrissey, "Developmental neurotoxicity evaluation of acrylamide in Sprague-Dawley rats," Neurotoxicology and Teratology, vol. 17, no. 2, pp. 189-198, 1995. 
[48] K. A. Conklin, "Dietary antioxidants during cancer chemotherapy: impact on chemotherapeutic effectiveness and development of side effects," Nutrition and Cancer, vol. 37, no. 1, pp. 1-18, 2000.

[49] R. O. Recknagel, J. E. A. Glende, and R. S. Britton, "Free radical damage and lipid peroxidation," in Hepatotoxicology, R. G. Meeks, S. D. Harrison, and R. J. Bull, Eds., pp. 401-436, CRC Press, Boca Raton, Fla, USA, 1991.

[50] A. A. Allam, A. W. El-Ghareeb, M. Abdul-Hamid, A. E. Bakery, M. Gad, and M. Sabri, "Effect of prenatal and perinatal acrylamide on the biochemical and morphological changes in liver of developing albino rat," Archives of Toxicology, vol. 84, no. 2, pp. 129-141, 2010.

[51] G. M. M. Rao, C. V. Rao, P. Pushpangadan, and A. Shirwaikar, "Hepatoprotective effects of rubiadin, a major constituent of Rubia cordifolia Linn.," Journal of Ethnopharmacology, vol. 103, no. 3, pp. 484-490, 2006.

[52] A. A. Allam, M. Abdul-Hamid, K. Zohair et al., "Prenatal and perinatal acrylamide disrupts the development of cerebrum and medulla oblongata in rat: biochemical and morphological studies," African Journal of Biotechnology, vol. 11, no. 29, pp. 7570-7578, 2012.

[53] M. Valko, D. Leibfritz, J. Moncol, M. T. D. Cronin, M. Mazur, and J. Telser, "Free radicals and antioxidants in normal physiological functions and human disease," The International Journal of Biochemistry and Cell Biology, vol. 39, no. 1, pp. 44-84, 2007.

[54] I. S. Young and J. V. Woodside, "Antioxidants in health and disease," Journal of Clinical Pathology, vol. 54, no. 3, pp. 176-186, 2001.

[55] A. A. Allam, A. El-Gareeb, M. Abdul-Hamid, A. El-Bakry, and J. Ajarem, "Acrylamide disrupts the development of Medulla oblongata in Albino rat: biochemical and morphological studies," African Journal of Pharmacy and Pharmacology, vol. 7, no. 20, pp. 1320-1331, 2013.

[56] Y. Yue, D. Zhang, S. Jiang et al., "LIN28 expression in rat spinal cord after injury," Neurochemical Research, vol. 39, no. 5, pp. 862-874, 2014. 


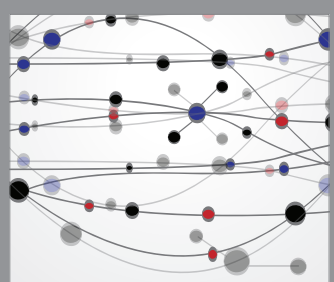

The Scientific World Journal
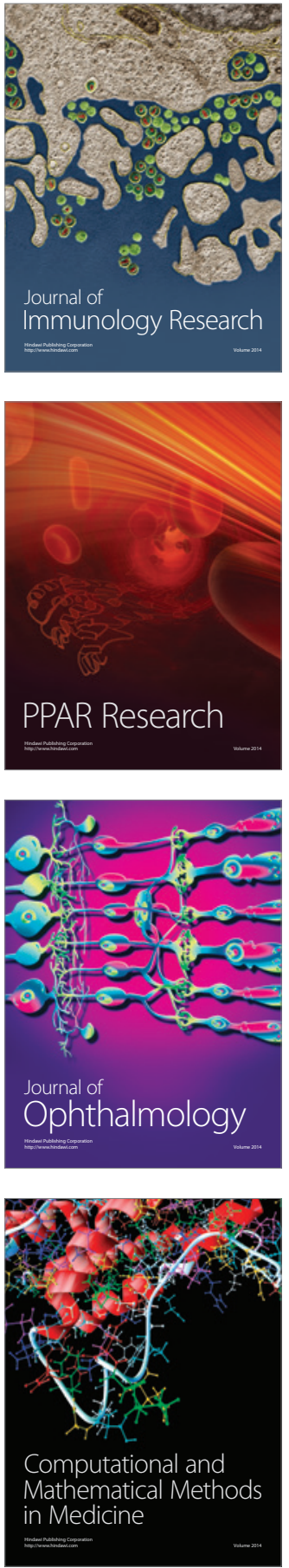

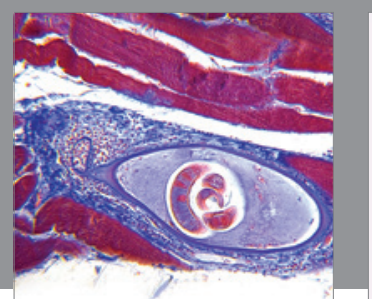

Gastroenterology Research and Practice

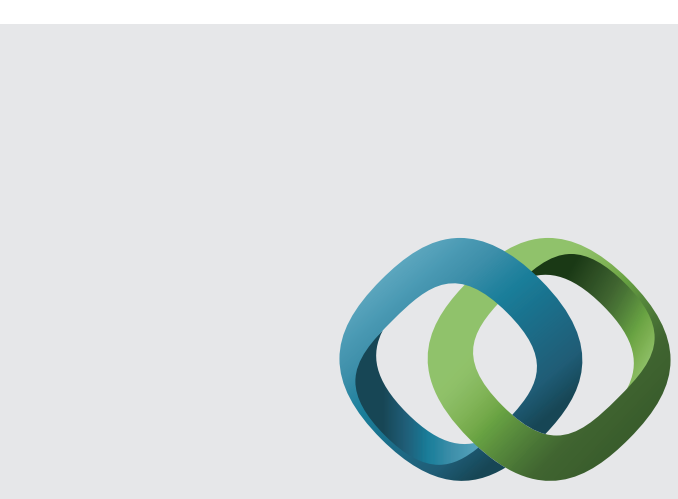

\section{Hindawi}

Submit your manuscripts at

http://www.hindawi.com
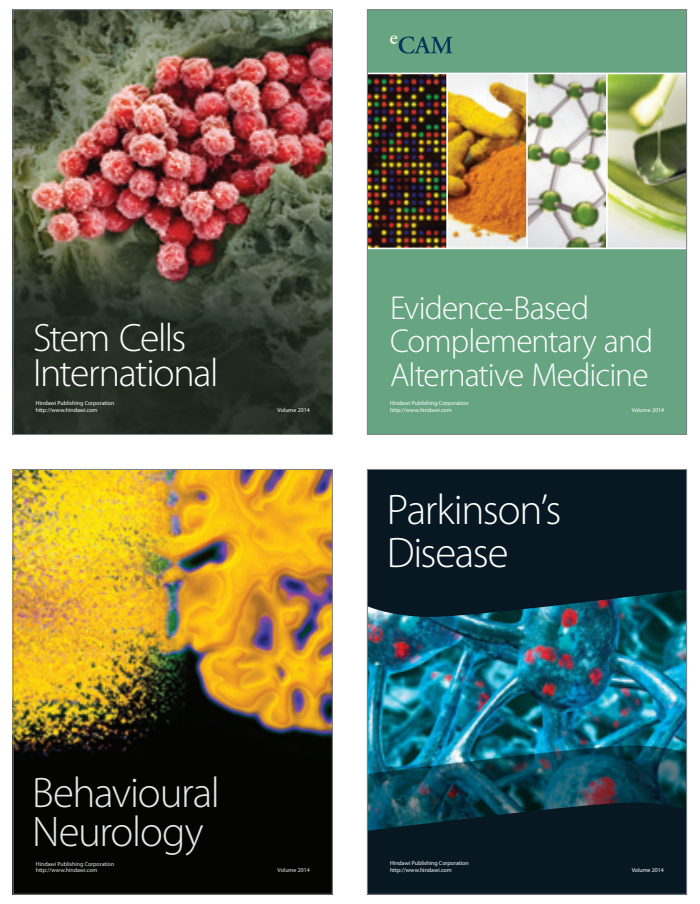
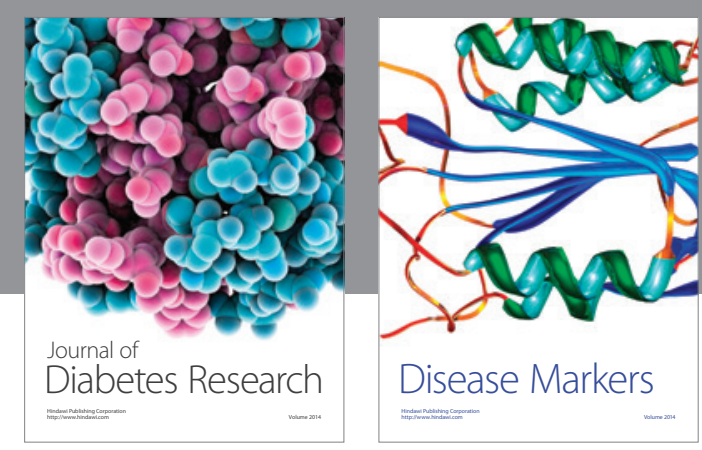

Disease Markers
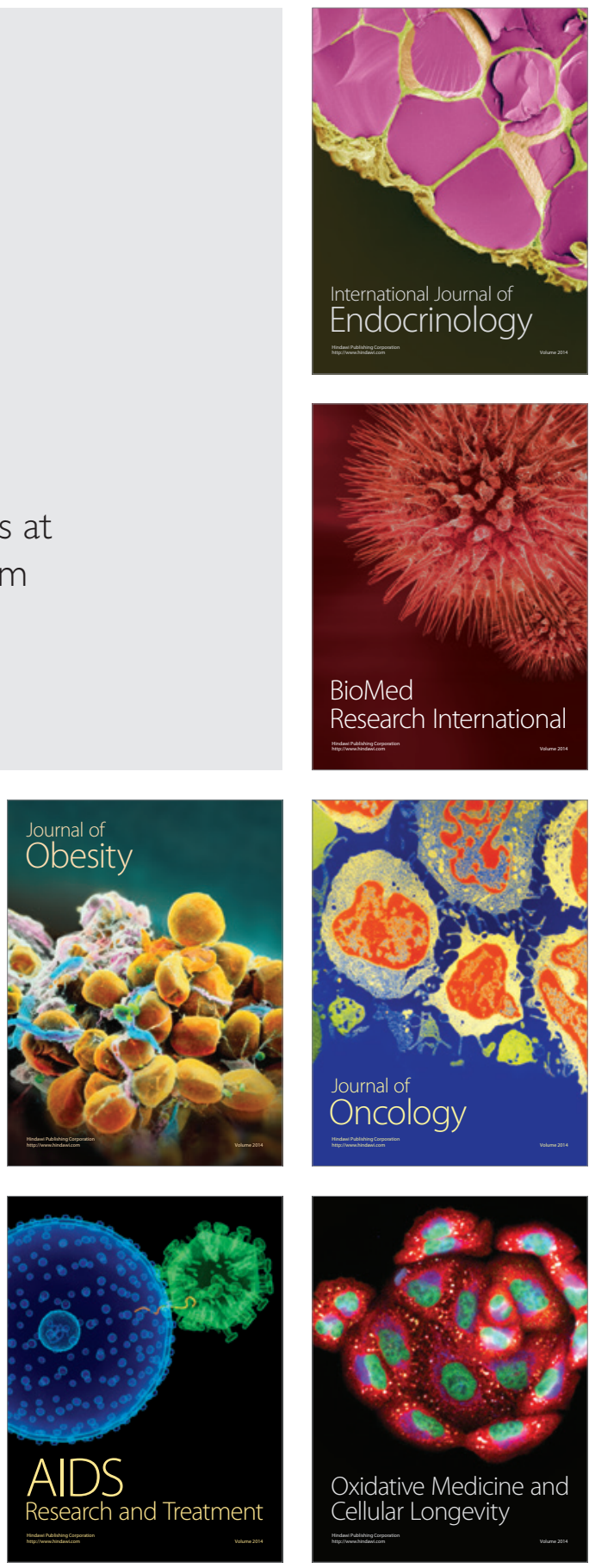